\title{
Erratum to "Dietary Quality and Comorbidities of Adults at Medical Risk for Diabetes" [Open Journal of Preventive Medicine 4 (2014) 138-144]
}

\author{
Joan A. Vaccaro, Daniela Safina, Lauren Grunspan, Fatma G. Huffman* \\ Department of Dietetics and Nutrition, Florida International University, Miami, USA \\ Email: $\underline{\text { huffmanf@fiu.edu }}$ \\ Received 2 February 2014; revised 4 March 2014; accepted 16 March 2014 \\ Copyright @ 2014 by authors and Scientific Research Publishing Inc. \\ This work is licensed under the Creative Commons Attribution International License (CC BY). \\ http://creativecommons.org/licenses/by/4.0/

\section{(c) (i) Open Access}

The original online version of this article (Vaccaro, J.A., Safina, D., Grunspan, L. and Huffman, F.G. (2014) Dietary Quality and Comorbidities of Adults at Medical Risk for Diabetes. Open Journal of Preventive Medicine, 4, 138-144. http://dx.doi.org/10.4236/ojpm.2014.44019) unfortunately contains a mistake. The authors wish to correct the errors in Table 4, page 142: P-value for the variable Special diet (yes) should read 0.081. And they added (yes) after Special diet for clarity. They moved Race/ethnicity up and presented it without an OR, for clarity.

Table 4

\begin{tabular}{ccc}
\hline Variable & OR $(95 \% \mathrm{CI})$ & $\mathrm{P}$ \\
\hline Race/ethnicity & - & 0.190 \\
Special diet (yes) & $1.46(0.95,2.23)$ & 0.081 \\
Race/ethnicity by special diet & - & 0.038 \\
MA—yes & $1.37(0.60,3.14)$ & 0.447 \\
MA—no & $1.99(1.19,3.35)$ & 0.011 \\
OH—yes & $1.68(0.58,4.94)$ & 0.332 \\
OH—no & $1.12(0.70,1.81)$ & 0.672 \\
BNH—yes & $1.96(0.62,6.21)$ & 0.242 \\
BNH-no & $0.58(0.35,0.97)$ & 0.037 \\
WNH (reference) & 1.00 & - \\
Age (years) & $1.02(1.01,1.03)$ & 0.001 \\
Males & $0.56(0.40,0.76)$ & 0.001 \\
\hline
\end{tabular}

\footnotetext{
${ }^{*}$ Corresponding author.
} 